\title{
A compulsory examination in pathology: redundant or necessary?
}

\author{
Jan G. van den Tweel • Claude Cuvelier • \\ Anthony J. Freemont
}

Received: 24 June 2012 / Accepted: 25 June 2012 /Published online: 8 July 2012

(C) The Author(s) 2012. This article is published with open access at Springerlink.com

In this issue Lehr et al. describe the compulsory examination used by the Swiss Society of Pathology to assess senior residents, and thereby assure the professional competence of its future qualified members [1]. With this examination, Switzerland is, with Britain, one of the few European countries with a comprehensive examination (lasting several days) that tests the full range of theoretical and practical competencies required of a medical specialist-pathologist.

There is considerable variation across Europe in the way that the final competencies of pathology trainees are assessed [2]. The reason for this variation is the fact that European countries are all entirely autonomous with regard to training, licensing and the issuing of specialty diplomas in postgraduate medical education. For example, in pathology six countries do not require any form of testing at all at the end of specialty training. In the remaining 26 there is considerable heterogeneity of testing [2], with autopsy competency tested in 11, gross specimen examination and sampling in 9 and cytology

\section{J. G. van den Tweel $(\square)$}

Department of Pathology, University Medical Center,

Heidelberglaan 100,

3508 GA Utrecht, The Netherlands

e-mail: j.vandentweel@umcutrecht.nl

C. Cuvelier

Department of Pathology, Ghent University,

9000, Ghent, Belgium

e-mail: Claude.Cuvelier@ugent.be

\section{A. J. Freemont}

Manchester Medical School, The University of Manchester,

Manchester, UK

e-mail: tony.freemont@manchester.ac.uk in 18. No exact data about the duration of these examinations are known.

Harmonization of training and the assessment of its effectiveness in producing competent specialists has proven to be very difficult because very few countries are willing to give up their autonomy to decide on the competencies of their medical specialists, to be acquired during residency training. This is in stark contrast to many countries where obligatory specialty examinations, sometimes with considerable failure rates, are the norm. Examples include the North American specialty boards and the examinations of the British Royal Colleges [3, 4]. For the Royal College of Pathologists, examinations are one of the principal benchmarks by which trainees are judged to have reached professional competence. The British examinations are still copied in one form or another by their old colonies (e.g. Australia, Canada, many African countries). When one of us (JGvdT) was an external examiner in Zimbabwe in the 90's it was much more difficult to become a pathologist there (or indeed a specialist in any medical discipline) than in the Netherlands and many other European countries. The same applies e.g. to Tanzania where, to progress further in the specialty, residents have to pass a general pathology examination already after 6 months of training.

To tackle this diversity in training and testing in 1997 the European Board of Pathology (EBP) of the European Union of Medical Specialists (UEMS), introduced an annual voluntary examination for senior pathology residents, based upon a similar examination successfully introduced by the European Board of Urology. Although introduction of the examination was supported by a large majority of the members of EBP, due to the lack of any consequence of failing, and poor support by senior pathologists, the test never really got off the ground and is currently taken by only a handful of people, mainly those from outside the EU hoping to 
increase their prospect of finding work as pathologist in Europe. The only exception is Malta where since 2011 the UEMS examinations are officially recognized for all medical specialisms.

With support of a grant from the EU, the European Association of Pathology Chairs and Program Directors (EAPCP) developed a voluntary progress test (EUROPALS) [5], comparable to the American RISE (Resident In Service Examination). The latter test is given for all medical specialties in the USA and is for pathology a good outcome predictor for the American Board Examination [6]. This EUROPALS test had a high participation rate and is now, thanks to the support of the European Society of Pathology being developed as an official progress test, not only for residents but also for specialised pathologists and subspecialists.

The relevant question here of course is why trainee medical specialists, including in pathology, in so many countries in Europe are not thoroughly tested at the end of their training. This is relevant in view of the results of the American and British examinations, showing that a proportion of advanced residents do not have the core competencies, as defined by senior members of the profession, considered necessary for practicing safely. As there is no suggestion that the training in the UK or USA is substandard, the question is relevant whether introduction of similar assessments across Europe would demonstrate lacunar competencies in some of the examined residents. That is not to suggest that trainees across Europe might be less competent than their North American or UK homologues, merely that as the experience in the e.g. USA and UK indicates, assessment stimulates learning. Creating a knowledgeable, thoughtful and competent pool of specialists is surely the fundamental goal of any postgraduate medical training programme.

Open Access This article is distributed under the terms of the Creative Commons Attribution License which permits any use, distribution, and reproduction in any medium, provided the original author(s) and the source are credited.

\section{References}

1. Lehr H-A, Moch H, Christen B, Safret A, Gugger M, Rössle M, von Gunten M, Lemoine R, Kurt AM, Caduff R, Arnold W, Singer G, Luscieti P, Bannwart F, Genton CY (2012) Board examination for anatomical pathology in Switzerland: two intense days to verify professional competence. doi:10.1007/s00428-012-1262-7

2. Bosman FT, van den Tweel JG (2009) Unison or cacophony: postgraduate training in pathology in Europe. Virchows Arch 454:497503

3. Picarsic J, Raval JS, Macpherson T (2010) United States Medical Licensing Examination step 1 two-digit score: a correlation with the American Board of Pathology first-time test taker pass/fail rate at the University of Pittsburgh Medical Center. Arch Pathol Lab Med 135:1349-1352

4. Gray TA (2009) The Royal College of Pathologists Annual Report of Examinations and Assessments undertaken in 2009 Dr. T.A. Gray. Director of Examinations and Assessment. http://www.rcpath.org/ Resources/RCPath/Migrated\%20Resources/Documents/A/ annual_report 2009.pdf

5. European Pathology Training Curriculum (2009) http://www.eapcp.org/ Europals/training.htm

6. Rinder HM, Grimes MM, Wagner J, Bennett BD, RISE Committee, American Society for Clinical Pathology and the American Board of Pathology (2011) Senior pathology resident in-service examination scores correlate with outcomes of the American Board of Pathology certifying examinations. Am J Clin Pathol 136:499-506 